\title{
Maintenance of responding by stimuli paired with response-independent food presentations
}

\author{
THOMAS R. LINSCHEID \\ Indiana University - Purdue University, Indianapolis, Indiana 46202
}

\begin{abstract}
A series of studies by Zimmerman and his co-workers has demonstrated that responding by pigeons may be maintained by stimuli (CR) paired with noncontingent food presentations. Because of the specific experimental procedures used, however, it is unclear whether or not the response must first be established with response contingent CR-food pairings. The present study demonstrates that establishement of the response by response contingent CR-food pairings is not a necessary condition and that response rates and schedule variation effects are similar in pigeons with and without histories of contingent CR-food pairings.
\end{abstract}

Conditioned reinforcement or the acquisition of response maintaining properties by previously neutral stimuli has been studied by several research methods (cf. Hendry, 1969; Kelleher \& Gollub, 1962). One such method described by Zimmerman and Hanford (1966) involves the maintenance of responding by stimuli paired with response independent food presentations. Zimmerman and Hanford used a one-key experimental space for pigeons and noncontingently presented access to grain via a variable interval schedule. Each grain presentation was accompanied by a set of discriminable stimulus changes. Responding to the key was reinforced by brief presentations of the stimulus changes which accompanied free grain presentations. It was demonstrated that responding could be maintained over long periods by the stimulus change configuration or conditioned reinforcer (CR) without the necessity of response contingent food-CR pairings. However, three of the four pigeons used in the 1966 study had been used previously in a study utilizing the same CR in which food-CR pairings had occurred response contingently, which brings up a question concerning the necessity of response contingent food-CR pairings for the development of the reinforcing properties of the $\mathrm{CR}$ in the noncontingent food-CR pairing paradigm. More simply stated: is a prior history of response contingent food-CR presentation a necessary condition for the development of responding by the $\mathrm{CR}$ in the Zimmerman-Hanford procedure? While the logical answer is that a history of response contingent presentations is not necessary, the empirical answer has not been presented. The present paper demonstrates that responding may be maintained by stimuli paired with noncontingent food presentations without a history of

This study was conducted while the author was supported by MH Postdoctoral Training Grant 10695. The author wishes to express thanks to Drs. Joe Zimmerman, who sponsors this paper and takes full editorial responsibility for it, and Peter Hanford for his assistance in preparing the manuscript and to Chris Milar for helping run the animals. Reprint requests should be sent to T. R. Linscheid, UAPCD, Georgetown University Hospital, 3800 Reservoir Road, N. W., Washington, D. C. 20007. contingent CR-food pairings.

\section{METHOD}

\section{Preexperimental Conditions}

Three initially naive white Carneaux pigeons (subjects) were maintained at $80 \%$ of their free feeding weight and run daily in a standard one-key experimental space for pigeons (Ferster \& Skinner, 1957). Subjects were shaped to keypeck for 4-sec access to grain. The response key was red during this condition and with the exception of the food hopper noise, no external stimulus changes were associated with grain delivery.

Subjects were run on a VI 1 schedule until stable response rates were observed (stable rates were defined as no discernable trend over a 5-day period) and then an extinction condition was introduced and remained in effect for five sessions. At the beginning of the third extinction session, a response contingent set of stimulus changes was introduced on a VI 1 scheudle and remained in effect during preexperimental Extinction Sessions 3, 4 , and 5. The 4-sec duration stimulus changes, later to be used as the conditioned reinforcer, consisted of: (1) a key light changed from red to green, (2) a low pitched tone (approximately $1000 \mathrm{~Hz}$ ), and (3) house lights off. This procedure was utilized to insure that the particular set of stimulus changes selected for use as the CR were indeed neutral and were not able to maintain responding in their own right.

\section{Experimental Conditions}

The following is a description of the sequential experimental conditions utilized in this study. Each subject remained in a condition until a stable response rate (defined above) was observed. Experimental conditions and their parameters are summarized in Table 1.

CR1. The first experimental condition involved a continuation of the response contingent (VI 1) stimulus change or conditioned reinforcement which had been introduced during the third preexperimental extinction session. Concurrently, response independent access to grain or free food (FF) was programmed to occur intermittently via a VI 6 tape. Each FF presentation lasted $4 \mathrm{sec}$ and was accompanied by the $\mathrm{CR}$ stimulus changes. In order to prevent superstitious reinforcement of keypecking by FF presentation, access to grain, if primed, was postponed for 6 sec by each keypeck.

CR2. In order to increase response rates and to bring the procedure more in line with the Zimmerman and Hanford studies, the duration of the response contingent $\mathrm{CR}$ presentations was reduced from $4 \mathrm{sec}$ to $1 \mathrm{sec}$. It was felt that the longer duration $C R$ presentation provided greater 
Table 1

Summary of Experimental Conditions and Number of Sessions in Each Condition for Pigeons 1W, 2W, and $3 W$

\begin{tabular}{lccccccc}
\hline & & \multicolumn{9}{c}{$\begin{array}{c}\text { CR } \\
\text { Dura- } \\
\text { Condi- }\end{array}$} & & & \multicolumn{3}{c}{ Sessions } \\
\cline { 5 - 8 } \multicolumn{1}{c}{ tion } & CR & FF & NS (Sec) & 1W & 2W & 3 3W \\
\hline CR1 & VI 1 & VI 6 & & 4 & 17 & 29 & 18 \\
CR2 & VI 1 & VI 6 & & 1 & 21 & 10 & 20 \\
CR3 & VI 1 & VI 12 & & 1 & 17 & 17 & 18 \\
NS & & VI 12 & VI 1 & & 19 & 19 & 19 \\
CR3 & VI 1 & VI 12 & & 1 & 25 & 24 & 21 \\
CR-EXT & EXT & VI 12 & & & 11 & 10 & 11 \\
CR3 & VI 1 & VI 12 & & 1 & 14 & 14 & 15 \\
\hline
\end{tabular}

Note $-C R=$ conditioned reinforcer,$F F=$ free food, $N S=$ novel stimuli.

opportunities for extinction of the $\mathrm{CR}$ and that the shorter $\mathrm{CR}$ presentation time would restrict the extinction of the CR and result in increased response rates. No change was made in the FF contingencies in this condition.

CR3. In order to further increase response rates and to test whether response rates using this procedure were comparable to those reported in studies utilizing response contingent food-CR pairing, the schedule for FF presentation was thinned from VI 6 to VI 12. This schedule was selected because of previously reported high rates of responding maintained by the VI 12 schedule (Zimmerman, 1969).

NS. To insure that responding was indeed being maintained by the conditioned reinforcing properties of the stimulus changes and not simply by stimulus change alone, response contingent CR presentations were eliminated and a novel set of stimuli changes was made contingent upon keypecking. The novel stimulus changes (NS) consisted of: (1) a high pitched tone (approximately $5000 \mathrm{~Hz}$ ), (2) flickering house lights; and (3) keylight off. The 1-sec duration NS change was programmed on a VI 1 schedule.

CR3. Return to CR3 condition to reestablish CR-response rates.

CR/EXT. Following a return to the CR 3 condition, extinction of the response contingent $C R$ presentations was instituted. The CR continued to be presented with the FF but was no longer presented as a result of keypecking. The condition served as a control for any possible response eliciting properties of FF presentation and as a further indication of the reinforcing properties of the CR.

CR3. To demonstrate that the reintroduction of the CR would bring the response rate up to previous levels, the CR3 condition was reinstituted.

\section{RESULTS}

The median response rates (responses per minute) for the five sessions prior to preexperimental extinction were $89.5,141.3$ and 58.0 for subjects $1 \mathrm{~W}, 2 \mathrm{~W}$ and $3 \mathrm{~W}$ respectively. Response rates for the 5 preexperimental extinction sessions are shown in Table 2.

No noticeable change in the extinction pattern occurred when the CR stimulus change was introduced response contingently during the third extinction session and response rates continued to decline in Sessions 4 and 5. This would indicate that the CR stimulus changes were not serving as a reinforcer prior to their pairing with food.
Table 2

Response Rates (RPM) for the Five Preexperimental Extinction Sessions

\begin{tabular}{clrrrr}
\hline & \multicolumn{6}{c}{ Preexperimental Extinction Session } \\
\cline { 2 - 6 } Pigeon & \multicolumn{1}{c}{1} & \multicolumn{1}{c}{2} & \multicolumn{1}{c}{3} & \multicolumn{1}{c}{4} & \multicolumn{1}{c}{5} \\
\hline 1W & 58.33 & 8.94 & 3.97 & 3.15 & 0.80 \\
2W & 99.1 & 40.47 & 22.38 & 15.32 & 0.30 \\
3W & 21.9 & 6.30 & 4.50 & 2.39 & 0.30 \\
\hline
\end{tabular}

Median response rates for the last five sessions in each experimental condition are presented in Figure 1. It is evident that the CR was capable of maintaining key peck behavior at rates comparable to those reported elsewhere (Zimmerman, 1969; Zimmerman, Hanford, \& Brown, 1967). It can also be seen that the highest rates of response occurred under conditions of short duration CR presentation and relatively sparse FF presentations which is also in agreement with the above cited results. In both of the two experimental control conditions (NS and CR EXT) response rates were substantially lower than CR3 responding indicating that the CR stimulus change had acquired reinforcing properties over and above those of either a novel stimulus change or no CR at all. It should be noted that, for subjects $2 \mathrm{~W}$ and $3 \mathrm{~W}$, response rates during NS were higher than during CR EXT indicating either that the pigeons were responding for stimulus change alone or that some amount of generalization from the $\mathrm{CR}$ stimulus change was occurring. Another interesting feature of the data is the substantially elevated response rates under CR3 conditions following the CR EXT condition for subjects

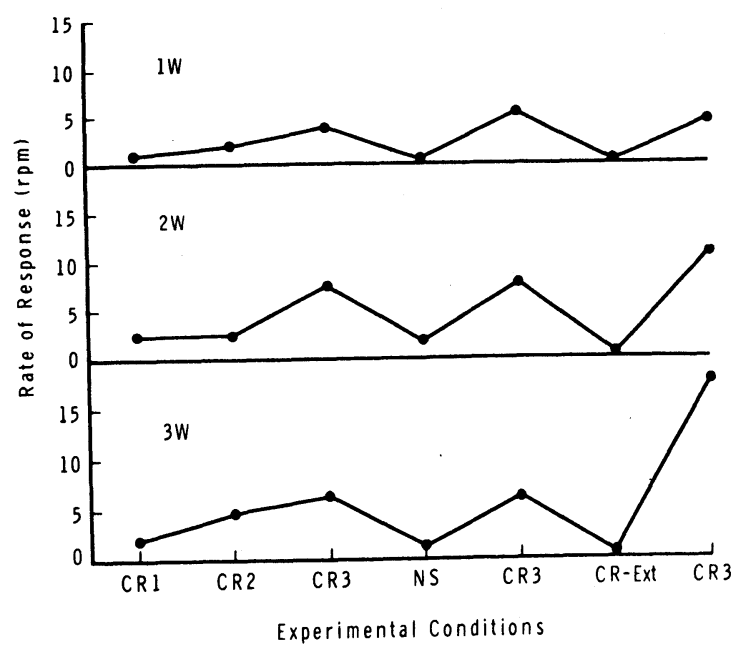

Figure 1. Median response rates for the last five sessions in each experimental condition for Subjects $1 W, 2 W$, and $3 W$.

$2 \mathrm{~W}$ and $3 \mathrm{~W}$. The nearly three fold increase for subject $3 \mathrm{~W}$ is particularly interesting and represents one of the highest rates reported. 


\section{DISCUSSION}

Results of this study clearly indicate that a prior history of response contingent food-CR parings is not a necessary condition for establishing CR maintained responding in the Zimmerman and Hanford one-key procedure. It further demonstrates that response rates are comparable to previously reported studies and respond similarly to parametric manipulations. The two control conditions point out that the strength of the response was directly related to the specific stimuli paired with food since responding dropped dramatically when a novel stimulus was introduced and during CR extinction. The dramatic increase in response rates for two of the subjects following CR extinction is hard to explain. It possibly could be a result of the nature of the $\mathrm{CR}$ extinction condition, namely, allowing CR-food pairings to continue thus strengthening the reinforcing properties of the CR while not allowing for the concommitant reduction in $\mathrm{CR}$ strength because the CR was not presented without the food.

\section{REFERENCES}

Ferster, C. B., \& Skinner, B. F. Schedules of reinforcement. New York: Appleton-Century, 1957.

Hendry, D. P. (Ed.), Conditioned reinforcement. Chicago: Dorsey, 1969

Kelleher, R. T., \& Gollub, L. R., A review of positive conditioned reinforcement. Journal of the Experimental Analysis of Behavior, 1962, 5, 543-597.

Zimmerman, J. Technique for sustaining behavior with conditioned reinforcement. Science, 1963, 142, 682-684.

Zimmerman, J. Meanwhile .... back at the key: Behavior sustained in an intermittent free feeding situation. In $D$. $P$. Hendry (Ed.), Conditioned reinforcement. Chicago: Dorsey, 1969.

Zimmerman, J., \& Hanford, P. V. Sustaining behavior with conditioned reinforcement as the only response-produced consequence. Psychological Reports, 1966, 1, 391-401.

Zimmerman, J., Hanford, P. V., \& Brown, W. Effects of conditioned reinforcement frequency in an intermittent free-feeding situation. Journal of the Experimental Analysis of Behavior, 1967, 10, 331-340.

(Received for publication September 27, 1974.)

\title{
Negative $S$ - contrast with minimal response requirements in $S+*$
}

\author{
STEPHEN WERK $†$ and JAMES H. McHOSE \\ Southern Illinois University at Carbondale, Carbondale, Illinois 62901
}

\begin{abstract}
Forty rats received runway and placement reward training in an experiment which factorialized, between subjects, the amount of runway and placement reward received on each trial. Speeds to the small runway reward were depressed by large reward placements and by a discrepancy between placement and runway reward amounts. The results suggest that the $S-$ contrast ef fect observed in differential conditioning occurs even when $S+$ response requirements are minimal and quite different from those in $\mathrm{S}-$.
\end{abstract}

Several differential instrumental conditioning studies have demonstrated that locomotor speeds to one cue (S1) are a function of the relationship between the reward magnitude contingent upon S1 running and the reward magnitude contingent upon running to the other

* Based in part on a thesis submitted by th e senior author to the Southern Illinois University Graduate School in partial fulfiliment of the requirements for the M.A. degree. Reprint requests should be sent to James $\mathrm{H}$. McHose, Department of Psychology, Southern Illinois University at Carbondale, Carbond ale, Illinois 62901

†Now at Laurentian University, Sudbury, Ontario, Canada. cue (S2) (cf. McHose, 1970). More specifically the discrepancy between an S+ reward magnitude and an Sreward magnitude typically produces $a_{\iota}$ depression of both $\mathrm{S}+$ and $\mathrm{S}-$ running speeds.

The purpose of the present study was to determine whether this discrepancy between S+ and S- reward magnitudes produces a depression of $\mathrm{S}$ - speeds in the absence of an S+ instrumental running response. Maxwell, Meyer, Calef, and McHewitt (1969) and Calef (1972) employed standard runway S- trials, while the $\mathrm{S}+$ trials consisted of placing the subjects directly at the 